\title{
Efficiency of using biostimulants Agrinos 1 and Agrinos 2 in adaptation of microplants of garden strawberry to ex vitro conditions
}

\author{
Marina Karpushina, Marina Winter, and Olesya Yaroshenko
}

Federal State Budget Scientific Institution «North Caucasian Federal Scientific Center of Horticulture, Viticulture, Wine-making», 39 str. 40 Let Pobedy, Krasnodar, 350901, Russia

\begin{abstract}
This article presents the results of experimental studies of the effect of biostimulants Agrinos 1 and Agrinos 2, containing strains of microorganisms Azotobacter vinelandii and Clostridium pasteurinum, etc., as well as a complex of nutrients (macro-, microelements, protein, amino acids, chitin, chitosan) on the activation of metabolic processes and reduction of stress effects on strawberry plants obtained by in vitro method. The effectiveness of the reaction of biostimulants on the adaptive processes of growth and development of microplants of garden strawberry varieties Alba, Kemiya, Clery has been studied. In the course of the research, a positive effect of biological products on the growth of the vegetative mass of plants was established: an increase in the height of the plants compared to the control by $20-25 \%$, the number of leaves by $25-$ $28 \%$ and an increase in the root system of plants by $30-40 \%$. In the Clery variety, the use of the biostimulants promoted the formation of the runners. In addition, the introduction of biostimulants into the soil contributed to the improvement of the quality indicators of the soil. The content of nitrate nitrogen in the soil increased by $18 \%$.
\end{abstract}

\section{Introduction}

Micropropagation of garden strawberries in vitro is becoming one of the most widely used methods in plant growing [1]. However, its obvious advantages can be easily leveled out due to problems and limitations arising in the process of work.

One of the main and problematic stages in the process of obtaining healthy strawberry planting material using micropropagation methods is the transfer of rooted plants obtained in vitro to non-sterile ex vitro conditions. A significant number of plants cultivated in vitro do not tolerate transfer from in vitro conditions to a greenhouse or open field. Plants grown in vitro are very delicate as the micropropagation process takes place under conditions of high humidity, controlled temperatures and low light intensity. In this regard, such plants lack protective mechanisms: waxy cuticle, stomata regulation, leaf hairs, which makes them very vulnerable to drying out under the influence of environmental conditions after plant transplantation from in vitro to ex vitro conditions [2].

Most plants grown under in vitro conditions require some acclimation period to ensure survival and vegetation growth when transferred to soil. 
In this regard, it is relevant to use natural biostimulants to improve the general health, growth and vitality of plants grown in vitro, as well as not causing any risks to the environment. In addition, improving the absorption of nutrients is one of the advantages of using biostimulants associated with their ability to increase the microbiological and enzymatic activity of the soil, due to the effect on the root structure, as well as the solubility and transportability of micronutrients [3-5].

Nitrogen bacteria are one of the components of biostimulants for horticultural crops. Biostimulants contain microorganisms that live freely in the soil, or are symbiotic with plants, and make a direct or indirect contribution to the nitrogen and phosphorus nutrition of plants. Nitrogen bacteria are capable of producing hormones, vitamins, and other substances necessary for the growth and development of plants. Microorganisms that are symbiotic and non-symbiotic in nature fix atmospheric nitrogen. According to a number of literature sources, the usage of Azotobacter chroococcum during the transplantation of plants from one condition to another, leads to a significant increase in the growth and productivity of crops. [6-15]

Considering these facts, this study was initiated to study the effect of biostimulants Agrinos 1 and Agrinos 2 on the growth, development, and adaptation of garden strawberries grown by in vitro method. as well as to study the effect of biostimulants on agrochemical characteristics of soil used for adaptation of garden strawberry plants to nonsterile ex vivo conditions.

\section{Materials and methods}

The studies were carried out in the adaptation phytotron of the Virology laboratory of the FSBSI NCFSIHVW in 2020-2021. Objects of research: microplants of garden strawberry varieties Kemiya, Alba and Clery, grown by in vitro method

The main characteristics of the used biostimulants: Agrinos 1 - is a product containing microorganisms, such as Azotobacter vinelandii and Clostridium pasteurinum, capable of producing and releasing organic acids as waste products, dissolving mineralized salts, and converting $\mathrm{K}+, \mathrm{Mg}+$, and $\mathrm{Ca}++$ from organic forms to mineral forms, more accessible to plants. Agrinos 2 is a microbial fermentation product containing L - amino acids (4\%), chitin, chitosan, glucosamine (4\%), enzyme complex, lactic acid, polysaccharides, carbon, nitrogen, and other essential trace elements used by plants to improve health and productivity during different stages of growth and development, as well as under different growing conditions. The biostimulants improve the tolerance of plants to various stresses (abiotic, biotic, and physiological) and supports the process of photosynthesis.

The introduction of biostimulants into containers with soil, where strawberry microplants were planted after transplanting them from sterile conditions in vitro to nonsterile ex vitro, was carried out once, by irrigation with an aqueous solution of the biostimulants Agrinos 1 at a concentration of $5 \mathrm{ml} / 1$, and after 7 days - Agrinos 2 (5 ml / , also once).

In the course of the experiment (45 days after watering), the indicators of plant growth were recorded. The length of the plants, the number of formed leaves, the length and the intensity of the root system formation were determined. Soil analysis was carried out by methods generally accepted in agrochemistry. The content of organic matter in the soil was determined by ashing in a muffle furnace at a temperature of $525 \mathrm{C}$ to constant weight. 


\section{Results and discussion}

As a result of the experimental studies, it was found that the length and the number of leaves of the strawberry plants in ex vitro 45 days after usage of biostimulants was significantly increased comparing to control plants. The maximum length of the most threated plants for strawberry variety Clery was $10.8 \mathrm{~cm}$, Kemiya $-9.8 \mathrm{~cm}$, Alba $-6.4 \mathrm{~cm}$. In the control variants, this indicator was lower by $25 \%, 23 \%$, and $20 \%$, respectively (Fig. $1,2)$.

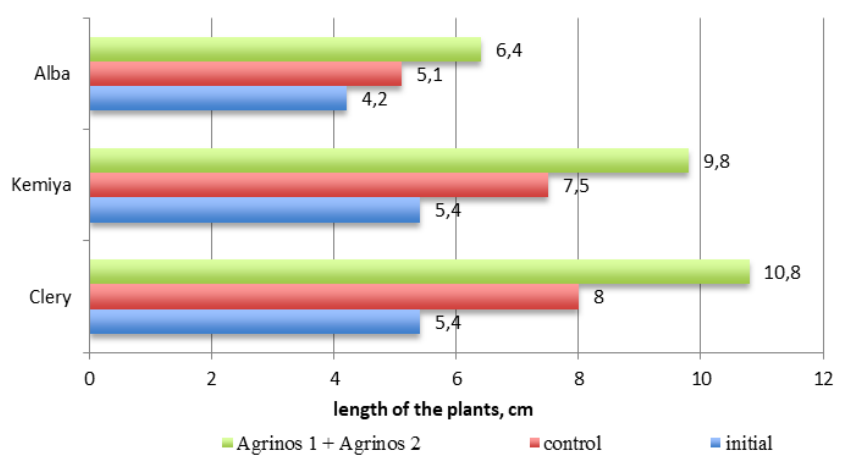

Fig.1. Influence of biostimulants Agrinos 1 and Agrinos 2 on the length of garden strawberry in the process of adaptation to non-sterile conditions

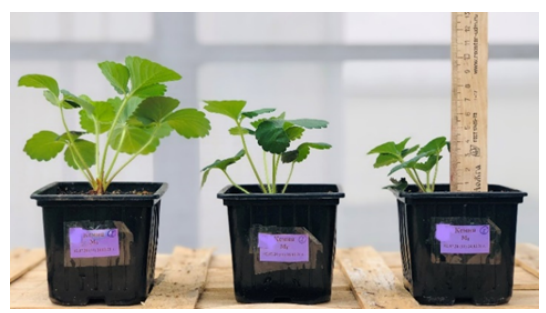

Control

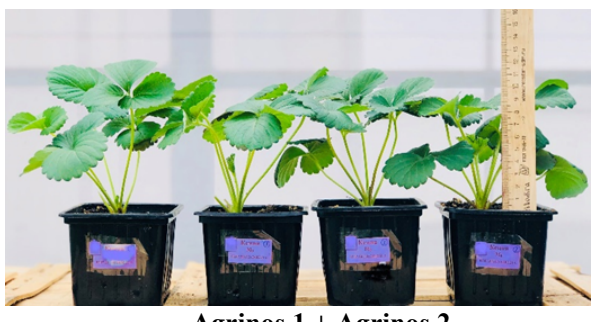

Agrinos $1+$ Agrinos 2

Fig. 2. Appearance of strawberry plants: control variant and variant with Agrinos $1+$ Agrinos 2, variety Kemiya

The increase in the number of leaves in the variants with the use of biostimulants was observed in all varieties 45 days after the application of the biostimulants. The average number of leaves in varieties Clery and Kemiya ranged from 6.6 to 7.3 leaves per bush, Alba - 7.6. In the control variants, this indicator was lower by $25-28 \%$ (Fig. 3, 4).

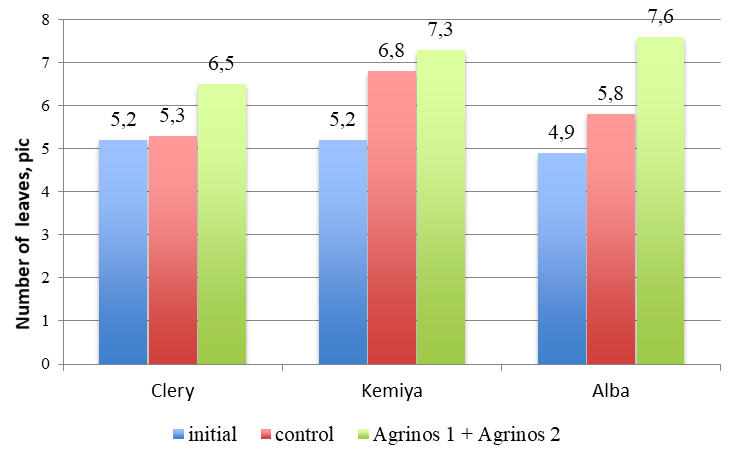

Fig. 3. Influence of biostimulants on the formation of vegetative mass of garden strawberry plants after 45 days 
It should be noted that all control variants of strawberry microplants had tendency of the leaf apparatus to dry out and die during the growth under ex vitro conditions, due to increased sensitivity to new environmental conditions, while this was not observed in the treated plants.

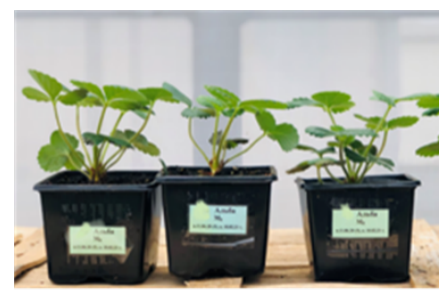

Control

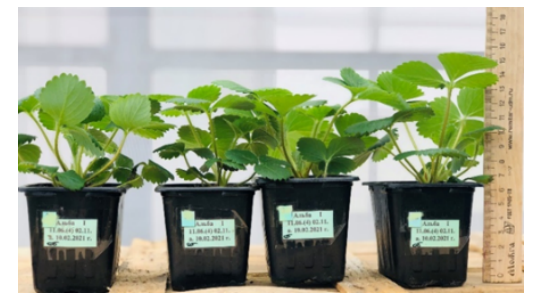

Agrinos $1+$ Agrinos 2

Fig. 4. Appearance of garden strawberry plants: control variant and variant with processing Agrinos 1 + Agrinos 2, variety Alba

The increase in green mass in treated plants can be associated with the formation of a large amount of chlorophyll upon the introduction of nitrogen fixers and with the production of plant growth regulators in the rhizosphere by bacteria, which are absorbed by the roots. Consequently, the enhancement of vegetative growth can be caused by increased biological nitrogen fixation. In the literature resources, there is information about an increase in the height of strawberry plants and the number of leaves when using Azotobacter [11].

In our studies, it was noted that the use of a complex of biostimulants Agrinos 1, containing active microorganisms and Agrinos 2, containing amino acids, a complex of enzymes and basic microelements, led to a significant improvement in root formation. The length of the root system in the variant with the use of biostimulants averaged $15-20 \mathrm{~cm}$, in the control variant the length of the roots varied within $4-10 \mathrm{~cm}$, depending on the variety (Fig. 5).

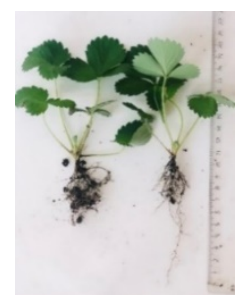

Control

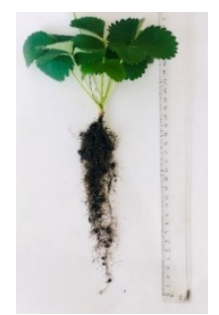

Agrinos $1+$ Agrinos 2

Fig. 5. Root system of garden strawberry plants: control variant and variant with treatment Agrinos 1 + Agrinos 2, variety Clery

In addition, in strawberries of the Clery variety, in the variant with biostimulants, an early onset of runners formation was noted. As early as 3 months after transplanting plants from in vitro conditions to ex vitro conditions, each plant of the Clery variety in the experimental variant had 2-3 runners, while in the control variant they were completely absent (Fig. 6). 


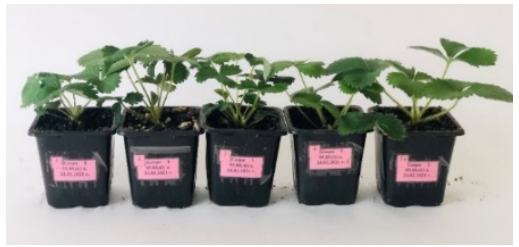

Control

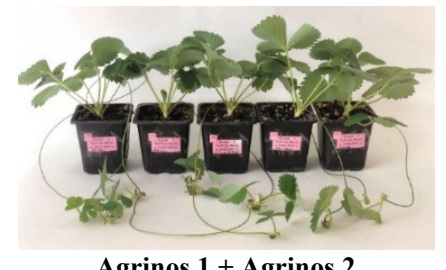

Agrinos $1+$ Agrinos 2

Fig. 6. Runner formation in garden strawberry, depending on the use of biostimulants, variety Clery

According to the literature, nitrogen fixation is one of the most important biological processes and is considered an interesting microbial activity on the soil surface, since it provides nitrogen recirculation and plays an important role in nitrogen homeostasis in the biosphere [14]. What's more, biological nitrogen fixation also helps maintain soil fertility and increase crop yields. It has been found that azotobacteria are useful organisms for use as bioinoculants and for studying the process of nitrogen fixation due to their ability to grow rapidly and quickly fix large amounts of nitrogen. Azotobacter is capable of converting atmospheric nitrogen into ammonia, which, in turn, is absorbed and utilized by plants [13].

In our experiment, the analysis of the control soil and the soil with the sequential introduction of biostimulants Agrinos 1 and Agrinos 2 was carried out. (Table).

Table 1. Soil analysis depending on the use of the biostimulants

\begin{tabular}{|c|c|c|c|c|c|}
\hline Varuant & $\mathrm{pH}$ & Organic matter, \% & $\begin{array}{c}\text { Nitrate } \\
\text { nitrogen, } \\
\mathrm{mg} / \mathrm{kg}\end{array}$ & $\mathrm{P}_{2} \mathrm{O}_{5} \mathrm{mg} / \mathrm{kg}$ & $\mathrm{K}_{2} \mathrm{Omg} / \mathrm{kg}$ \\
\hline $\begin{array}{c}\text { Agrinos 1 and } \\
\text { Agrinos 2 }\end{array}$ & 7,18 & 32,34 & 300,8 & 118,50 & 772,19 \\
\hline Control & 7,12 & 29,21 & 253,5 & 110,06 & 899,24 \\
\hline
\end{tabular}

The chemical analysis showed that introduction of biostimulants into the soil increased the content of nitrate nitrogen by $18 \%$.

\section{Conclusion}

Based on the obtained data, a significant effect of the biostimulants Agrinos 1 and Agrinos on the adaptive ability of microplants of garden strawberries grown in vitro conditions. The studies showed that the intensity of vegetative growth in the treated variants was $20-25 \%$ higher than in the control. The plants had a stronger root system $(5-10 \mathrm{~cm}$ longer than in the control), and, consequently, a higher adaptive ability to ex vitro conditions. The usage of these biostimulants influenced the content of mineral nitrogen available to plants in the soil. The amount of nitrate nitrogen increased by $18 \%$

\section{References}

1. K. Ben Mahmoud, A. Najar, E. Jedid, N. Jemai, A. Jemmali, J. New Sci. Agri. Biotech., 47(2), 2564-2676 (2017) https://www.jnsciences.org/agri-biotech/69-volume-47/384tissue-culture-techniques-for-clonal-propagation,-viral-sanitation-and-germplasmimprovement-in-strawberry-fragaria-X-ananassa-duch.html 
2. A. Batukaev, S. Kornatskyi, T. Minkina; A. Barbashev, S. Sushkova, Int. Mult. Sci. GeoConference: $\quad$ SGEM, 19(6.1), 737-746 https://doi.org/10.5593/sgem2019/6.1/S25.095

3. A. Aasfar, A. Bargaz, K. Yaakoubi, A. Hilali, I. Bennis, Y. Zeroual, K.I. Meftah, Front. Microbiol., (2021) https://doi.org/10.3389/fmicb.2021.628379

4. A Efthimiadou., N. Katsenios, S. Chanioti, M. Giannoglou, N. Djordjevic, G. Katsaros, Sci. Rep., 10, 21060 (2020). https://doi.org/10.1038/s41598-020-78034-6

5. R. Hindersah, N.N. Kamaluddin, S. Samanta, S. Banerjee, J. Soil Sci. Agroclimat., 17(2), 170-179 (2020) https://doi.org/10.20961/stjssa.v17i2.45130

6. D. Rueda, G. Valencia, N. Soria, B.B. Rueda, B. Manjunatha, R.R. Kundapur, M. Selvanayagam, J. App. Pharm. Sci., 6(01), 48-54 (2016) https://doi.org/10.7324/JAPS.2016.600108

7. F. Gooshchi, World App. Sci. J., 21, 1176-1180 https://doi.org/10.5829/idosi.wasj.2013.21.8.2702

8. G. Colla, Y. Rouphael, R. Canaguier, E. Svecova, M. Cardarelli, Front. Plant. Sci., 5, 448 (2014) https://doi.org/10.3389/fpls.2014.00448

9. J.C. Setubal, P. Dos Santos., B.S. Goldman, J. Bacteriol., 191, 4534-4545 (2009) https://doi.org/10.1128/JB.00504-09

10. S.A. Wani, S. Chand, T. Ali, Curr. Agri. Res. J., 1(1), $35-38$ (2013) http://doi.org/10.12944/CARJ.1.1.04

11. V.K. Tripathi, K. Sanjeev, A.K. Gupta, Ind. J. Hortic, 72(2), 201 (2015) https://doi.org/10.5958/0974-0112.2015.00039.0

12. A. Sumbul, R.A. Ansari, R. Rizvi, I. Mahmood, Saudi. J. Biol. Sci., 27(12), 3634-3640 (2020) https://doi.org/10.1016/j.sjbs.2020.08.004

13. K. Prajapati, K.D..Yami, A. Singh, Nepal J. Sci. Tech., 9, 85-90 (2010) https://doi.org/10.3126/njst.v9i0.3170

14. S.A. Wani, S. Chand, M.A. Wani, M..Ramzan, K.R. Hakeem, In: K. Hakeem, J. Akhtar, M. Sabir (eds.) Soil Science: Agricultural and Environmental Prospectives, 333-348 (Springer, Cham, 2016) https://doi.org/10.1007/978-3-319-34451-5_15

15. F. Romero-Perdomo, J. Abril, M. Camelo, A. Moreno-Galván, I. Pastrana, D. RojasTapias, R. Bonilla, Rev. Argent. Microbiol., 9(4), 377-383 (2017) https://doi.org/10.1016/j.ram.2017.04.006 